\title{
German Fever. Beckett in Deutschland/ Beckett in Germany/ Beckett en Alemania
}

Vanesa Cotroneo

Universidad Friedrich Alexander Erlangen, Nürnberg

"I am reading German and learning a little that way. Always when its [sic] coming up to Xmas I get the German fever for the Tannenbäumchen [little fir trees] und Bierreisen [beer trips] through the snow" (citado por Nixon: 2011, p.13), le había confesado Samuel Beckett a su amigo y continuo destinatario de las cartas del período correspondiente a los años ‘30, Thomas MacGreevy. Una German Fever que, como su nombre lo indica, supone un estado de efervescencia caracterizado por la excitación, las emociones fuertes, los delirios pero, también, los malestares y las tristezas. Una German Fever que, durante las navidades y en vínculo con la melancolía, remite a las caminatas de Beckett junto a su padre por las montañas de Dublín. Desde la ausencia del mismo, Alemania le ofrecerá a Beckett lo que especialistas denominan un espacio de intensidad emocional, tanto buena como mala (Nixon: 2011, p.16).

En referencia dicha expresión y en colaboración con la Universidad de Reading, Inglaterra, montaron los críticos e investigadores beckettianos Mark Dixon y Dirk Van Hulle, la exposición German Fever. Beckett in Deutschland/ Beckett in Germany, en el Museo de Literatura Moderna de Marbach, Alemania, entre el 8 de noviembre de 2017 y el 14 de octubre de 2018 . La exposición, que exhibía fotografías, manuscritos y correspondencia, presentó la obra de Samuel Beckett en su vínculo con Alemania, agregándole un catálogo explicativo elaborado por ambos estudiosos, editado por las colecciones Marbachermagazin.

Acorde a los criterios establecidos por Nixon y Van Hulle, la exposición se mueve cronológicamente en cinco secciones, momentos puntuales de lo que llamamos "Beckett en Alemania", desde las visitas del joven a su familia en Kassel y sus acercamientos al lenguaje literario alemán, pasando por la escritura de los seis diarios alemanes redactados en inglés y alemán durante los seis meses de su viaje de formación (octubre de 1936- abril de 1937) o, como lo ha llamado James Knowlson, su "peregrinaje artístico" (Knowlson: 1996, p.232); luego, la colaboración y amistad constante con editores y traductores de la Suhrkamp Verlag (1953-1989), las producciones en el Schiller-Theater de Berlín (1967-1978) y, finalmente, la producción para medios como radio y televisión en la Süddeutsche Rundfunk de Stuttgart (1973-1981).
En lo que respecta a la primera sección o capítulo, Annäherungen an eine deutsche Literatursprachel Approaches toward a German Literary Language, "Aproximaciones a un lenguaje literario alemán"1, se presentan manuscritos de Beckett, entre los cuales se encuentran un cuaderno de vocabulario alemán titulado German Vocabulary Notebook (1934-1937, UoR $^{2}$ ) y el cuaderno llamado The Whoroscope Notebook (1932-1938, UoR); transcripciones hechas por el autor, a mano y con color rojo, de A History of German Literature, de J.G. Robertson (1934, TCD), notas sobre Albrecht Dürer (UoR) y el Fausto de Goethe (1936, UoR); copias mecanografiadas del Prometeo de Goethe (1935, TCD) y páginas anotadas de los trabajos completos, Gesammelten Werke, de Hölderlin (UoR). También se presenta el poema Cascando en traducción al alemán, del 18 de agosto de 1936 (UoR) y un primer fragmento teatral escrito en alemán, Mittelalterliches Dreieck (1936, UoR). Estos primeros trabajos de traducción, interpretación y producción escrita, nos muestran a un joven Beckett intentando encontrar su poética personal, luchando con el lenguaje y su significado.

En la segunda sección, German Diaries: Becketts Reise durch Deutschland/ Beckett's German Diaries- a Journey through Nazi Germany, 1936-37, "Los diarios alemanes de Beckett- un viaje a través de la Alemania nazi", se exhiben manuscritos de los German Diaries, como también un mapa de Berlín del año 1936; cartas en inglés y alemán, junto con postales de sus pintores favoritos dirigidas a Günter Albrecht, librero de Hamburgo a quien Beckett conoció en su peregrinaje. Recordemos que Beckett le dedica a Axel Kaun, librero de Berlín, la German Letter, también del período, en la cual postula la idea de una literatura de la despalabra. Estas y otras postales con motivos pictóricos y escultóricos reflejan el interés beckettiano por las artes visuales como posible remedio frente la despalabra. La pintura, la escultura y la arquitectura conforman los materiales en los cuales

\footnotetext{
1. Todas las traducciones al castellano de los títulos y/o fragmentos bilingües, alemán y/o inglés, me pertenecen.

2. Las abreviaturas UoR, TCD y DLA corresponden a los archivos de Beckett en University of Reading, Trinity College Dublin y Deutsches Literaturarchiv Marbach, respectivamente.
} 
Beckett se apoya para, justamente, representar la dificultad por transmitir verbalmente su experiencia visual. Al respecto, Beckett le había escrito una carta a MacGreevy desde Hamburgo, junto con una postal (incluida entre las exhibidas, correspondientes a los años 1936-1937, TCD) diciendo que cuando haya visto las pinturas y luchado lo suficiente con el lenguaje, no lamentaría irse de Alemania. El contexto de censura, la futura exhibición nazi del llamado "Arte degenerado", integrada por obras que supuestamente ofendían el sentimiento nacional alemán pero que Beckett pudo ver en colecciones privadas, hicieron que surja en el autor la idea del filósofo inglés Berkeley según la cual ser, es ser visto, ser percibido (Nixon: 2011, p.138). En cuanto a sus preferencias pictórico-escultóricas, Beckett se inclinaba por imágenes cuyos contenidos presentaban un elemento de reticencia, como las de los pintores flamencos del siglo XVII, de Kaspar David Friedrich o de Dürer; reticencia que puede reconocerse en la escultura alemana de tipo eclesiástico de tonalidades grises pero expresión humana, la cual cobrará tridimensionalidad su posterior obra teatral y audiovisual.

La tercera sección se titula Suhrkamp: "Eine Art von Heimat" / Beckett and Suhrkamp, "Suhrkamp, "una especie de hogar'”, donde se detalla el vínculo de Beckett con la editorial Suhrkamp, establecido desde 1953 hasta la muerte del autor, en 1989. Luego de unas primeras presentaciones de En attendant Godot, en París, Peter Suhrkamp se aproxima a Beckett para proponerle incluir su obra en el sello, tomando a Elmar Tophoven como traductor, residente en París. Beckett acepta y, aunque no encuentra las primeras versiones de Tophoven demasiado buenas, prefiere no desilusionar al grupo y propone un trabajo en conjunto, donde autor y traductor se reunirían para continuar traduciendo juntos. En el año 1958, Siegfried Unseld se suma como socio al sello editorial y comenzaría un trabajo brillante, más una amistad que el propio Beckett apreciaría, apodando a Unseld, “Dr. Suhrkamp". El mismo Unseld, años más tarde, calificaría a Beckett como "Nummer 1 aller Autoren", es decir, el número 1 (uno) de todos los autores. La exposición de Nixon y Van Hulle presenta varios documentos del período, como cartas mecanografiadas entre Beckett y Peter Suhrkamp en alemán, entre Beckett y Unseld en alemán y francés, copias de versiones de En attendant Godot en francés, anotadas por el autor, más copias de las primeras versiones al alemán corregidas o tachadas por Tophoven, seguramente, parte del proceso de traducción conjunta. Entre las cartas de Unseld dirigidas a Beckett, se encuentra la invitación a una Verlagsabend o tarde de la editorial de 1959, donde los autores leerían sus trabajos frente al público pero que Beckett, fiel a su estilo reservado, prefirió rechazar, negociando luego la confirmación de su asistencia y propuesta de lectura por parte del traductor, Tophoven. De ese modo, en el año 1961 se realiza otra Verlagsabend, titulada Hommage à Beckett, donde se amplía la lista de invitados a presentar sus trabajos y participa nada menos que Theodor Adorno, a quien Beckett había conocido en París en 1958, por medio de Unseld y quien fue presentado entonces como “'Unser Verlagsautor' ['a Suhrkamp author'] and a German intellectual champion" (Nixon y Van Hulle: 2017, pp.215-216). En aquel encuentro en París, Adorno le había entregado a Beckett un ejemplar dedicado de sus Noten zur Literatur, publicadas por Suhrkamp. En el homenaje del 27 de febrero de 1961 (7.Suhrkamp-Verlagsabend), Adorno presenta su ponencia titulada luego Versuch, das 'Endspiel' zu verstehen. Dicha tarde, durante su discurso de apertura -texto incluido en la exposición de Nixon y Van Hulle-, Unseld introduce la interpretación filosófica que el Profesor Adorno dará sobre Endspiel, los vínculos de la obra de Beckett con el aspecto filosófico del lenguaje según Wittgenstein, y a Samuel Beckett como un autor necesario. El vínculo Unseld-Beckett se evidencia como uno de los más fructíferos en la obra de ambos, pues le permitió a Beckett entender a la editorial Suhrkamp como una forma de hogar, al cual siempre podía regresar para experimentar traducciones y versiones, a menudo elaboradas a la par del trabajo con sus nuevos dos socios alemanes: el Schiller-Theater Berlin y la Süddeutsche Rundfunk de Stuttgart.

'Blosses Spiel': Beckett am Schiller-Theater Berlin/ Beckett directs at the Schiller-Theater Berlin, “'Obra pura': Beckett en el teatro Schiller de Berlín”, es el título de la cuarta sección, y se focaliza en los procesos de puesta en escena de obras beckettianas en el mencionado teatro de la capital alemana. Si bien ya en 1965 Beckett había asistido en la puesta de Warten auf Godot bajo la dirección de Deryk Mendel en el Schiller-Theater Berlin, es a partir del año 1967 que Beckett comienza a dirigir sus propias obras allí, primeramente, en el Werkstatt o sala-taller y, luego, en la sala principal. Su debut como director en este teatro tiene lugar con la puesta de Endspiel, en octubre de $1967^{3}$. En esta etapa, el autor se concentra en una especie de traducción escénica ${ }^{4}$ ya que, a través de

\footnotetext{
3. Endspiel en el Schiller-Theater Berlin, en 1967, contó con las actuaciones de Ernst Schröder (Hamm), Horst Bollmann (Clov), Werner Stock (Nagg) y Gudrun Genest (Nell).

4. La Dra. María Inés Castagnino, tras la conferencia del Prof. Dr. Juan Jesús Zaro, "Luis Astrana Marín, traductor de Shakespeare", organizada por el Dr. Lucas Margarit para la Maestría de Literaturas en Lenguas Extranjeras y Literaturas
} 
las puestas que él mismo dirige, los cambios definitivos de sus obras son sellados, como es el caso de la escena de Endspiel sobre la observación del entorno con el catalejo, en la que Clov le dice tres veces a Hamm, que ve "nada" / "Nichts" y, posteriormente, que todo está "Kaputt!" / "roto", expresión modificada durante los ensayos por el monosilábico "Aus!" / "fin" (Haerdter: 1969, p.99). Algo de esta modalidad había comenzado a vislumbrarse en 1964, cuando Beckett le escribió a Unseld desde Londres, donde se encontraba para asistir y aconsejar en los ensayos de Play: "I shall never give another theatre text, if there ever is another, to be published until I have worked on it in the theatre" (Beckett, 19/03/1964, DLA, citado por Nixon y Van Hulle: 2017, p.113). Sin embargo, ningún texto es definitivo puesto que, como indica Knowlson en la nota editorial de los tomos The Theatrical Notebooks of Samuel Beckett, las decisiones de Beckett como director se encuentran determinadas por circunstancias variables, ya sea por el tipo de actores como por las limitaciones de la escena y, como precisa Gontarski en la introducción al Tomo II. Endspiel, "Writing, translating and directing were of a piece, part of a continuous creative process" (Gontarski: 1992, p.13). Desde el momento en que Beckett encuentra al director teatral dentro suyo, dirige en el Schiller-Theater Berlin siete de sus obras: Ensdpiel (1967), Das letzte Band (1969), Glückliche Tage (1971), Warten aufGodot (1975), Damals/ Tritte (1976) y Spiel, esta última, presentada junto a Kommen und Gehen, dirigida por Walter Asmus (1978) (Nixon y Van Hulle: 2017, p.222). Para complementar, vale decir que los trabajos de dirección de Beckett en Berlín fueron momentos particularmente especiales, registrados por la cámara fotográfica de Rosemarie Clausen. Sus instantáneas fotográficas ilustraron el programa de mano de la obra y fueron parte de una publicación de la editorial Suhrkamp titulada Samuel Beckett inszeniert das "Endspiel", "Samuel Beckett pone en escena Fin de partida", la cual cuenta con la traducción de Tophoven más un diario de ensayos elaborado por el asistente de Beckett en el Teatro Schiller, Michael Haerdter, titulado "Über die Proben für die Berliner Aufführung. 1967" ["Sobre los ensayos para la actuación de Berlín. 1967"], presentando un minucioso registro de los mismos. Los especialistas Nixon y Van Hulle, exponen en esta sección dichas fotografías de Clausen, el folleto de la obra Warten

Comparadas de la UBA [19/05/2021], se refirió al concepto de "performability" o "speakability" respecto de las traducciones teatrales de Shakespeare, realizadas por Lautaro Vilo en Argentina. Para el concepto de traducción escénica, también puede consultarse Cotroneo,V. (2013) "El teatro de Samuel Beckett: la puesta en escena como traducción", Actas del VI Congreso ATEACOMP. Disponible en: https://drive.google.com/drive/folders/0B-NMsqme2CAoa1QyRDAyUHIPNTg $[02 / 06 / 2021]$ auf Godot (1975, DLA), dos cuadernos de notas de actuación hechas por Beckett en relación a las puestas de Endspiel (1967, UoR) y de Warten auf Godot en el Teatro Schiller (1975, UoR), la tapa de la publicación de Suhrkamp mencionada (1969, DLA), junto a la nota mecanografiada de la charla de taller entre Unseld y Beckett, acerca de la puesta en escena de Endpiel en 1967. Esta última había consistido en dos preguntas de Unseld acerca de la responsabilidad del autor para resolver el desconcierto de su puesta “1. (...) Glauben Sie, daß 'Endspiel' den Zuschauern Rätsel aufgibt? 2. Sind Sie der Meinung, daß der Autor eine Lösung der Rätsel parat haben muß?”, ante lo cual Beckett responde:“'Endspiel' will bloßes Spiel sein. Nichts weniger. Von Rätseln o. Lösungen also kein Gedanke. Es gibt für solches ernstes Zeug Universitäten, Kirchen, Cafés du Commerce usw."5 (Copia mecanografiada de la charla de taller, 03/10/1967, DLA).

Finalmente, Eine neue Sprache: Beckett und der SDR/ Beckett and the Süddeutsche Rundfunk, "Un nuevo lenguaje: Beckett y la Süddeutsche Rundfunk”, presenta el trabajo del autor en relación con los medios audiovisuales, reconociendo que el significado de un texto también depende de sus medios de realización. Como señalan Nixon y Van Hulle, "Beckett wiederum ist darauf bedacht, seine Ideen nicht nur durch dieses neue Medium, sondern selbstreflexiv mit ihm zu verwirklichen"6 (Nixon y Van Hulle: 2017, p.159). Es por ello que, durante esta etapa, Beckett trabaja en colaboración con la SDR, especialmente con Reinhart Müller-Freienfels, quien estaba a cargo de la sección televisiva dentro de la emisora. Müller-Freienfels había montado una serie de emisiones Ilamadas Der Autor als Regisseur ("El autor como director") y, en 1965 , le ofrece a Beckett la oportunidad de dirigir sus propias obras para TV, brindándole toda la asistencia técnica necesaria. De este modo, el autor realizó siete proyectos junto a la Süddeutsche Rundfunk de Stuttgart, en los cuales la visualidad y lo performático ocupan un rol central, desde Eh Joe (1966) hasta Was wo (1983), pasando por Geistertrio (Trío fantasma) y ...nur noch Gewölk... (... but the clouds...), proyecto transmitido junto con la producción de la BBC de Not I (1973). Completan la lista Quadrat, la versión televisiva de Quad (1981) y Nacht und Träume, de título alemán pero texto en inglés (1982). Acerca de estas

\footnotetext{
5. (...) ¿Cree Usted que Fin de partida es un acertijo para la audiencia? 2. ¿Opina Usted que el autor debe dar una solución para dicho acertijo?, ante lo cual Beckett responde: "Fin de partida es una obra pura. Nada menos. No pensé en acertijos o soluciones. Para esas cosas serias existen las universidades, iglesias, cafés, etc."

6. "Beckett, por otro lado, es cuidadoso en presentar sus ideas no sólo a través de estos nuevos medios, sino en trabajar de una manera autoreflexiva con ellos".
} 
dos últimas producciones, unos intercambios epistolares con Helene Ritzerfeld, de la Suhrkamp Verlag, dan cuenta de la intransigencia del autor en detalles puntuales. Ante la pregunta de la editorial en el año 1981 sobre si Quadrat podría montarse en teatro, Beckett responde, en su característico estilo directo y categórico, "Quadrat is for TV only" y, ante una siguiente pregunta, en 1982, acerca del uso de la lengua inglesa en Nacht und Träume, Beckett explica que el idioma del texto es el inglés, con el título en alemán derivado de la obra de Schubert, Lied, cuya letra pertenece a Von Collin. La exposición de Nixon y Van Hulle exhibe dichos intercambios (1981/1982, DLA), así como también la invitación de Müller-Freienfels enviada a Beckett para producir sus obras para TV en la Süddeutsche Rundfunk Stuttgart (1976, DLA), además de epístolas intercambiadas entre ambos, manuscritos de Quad/ Quadrat (1981, UoR), copias mecanografiadas de Nacht und Träume (1983, DLA), notas y comentarios sobre las producciones de Was wo (1985, UoR) y el manuscrito del poema Ne manquez pas à Stuttgart, compuesto por Beckett sobre sus paseos al estilo flâneur por la Neckarstraße (1977/78, UoR), posteriormente incluido en sus Mirlitonnades.
Sin dudas, el trabajo de Nixon y Van Hulle, German Fever. Beckett in Deutschland (2017-2018), es una puerta de ingreso a un riquísimo universo beckettiano que continuará explorándose.

\section{Bibliografía}

"Gontarski, S. (1992) The Theatrical Notebooks of Samuel Beckett. Volume II. Endgame. General Editor: Knowlson, J. Londres: Faber \& Faber.

» Haerdter, M. (1969). “Über die Proben für die Berliner Aufführung. 1967”. En Samuel Beckett inszeniert das "Endspiel«. Frankfurt am Main: Suhrkamp.

» Knowlson, J. Damned to Fame (1996). Londres: Bloomsbury.

»Nixon, M. (2011). Samuel Beckett's German Diaries 1936-1937. Londres: Continuum.

"Nixon, M. y Van Hulle, D. (2017). German Fever. Beckett in Deutschland. Marbach: Marbachermagazine. 